DOI 10.37882/2223-2982.2020.08.08

\title{
ЗНАЧЕНИЕ ЭТНОКУЛЬТУРНОГО КОМПОНЕНТА В ПРОЦЕССЕ ОБУЧЕНИЯ КИТАЙСКИХ СТУДЕНТОВ РУССКОМУ ЯЗЫКУ
}

\section{THE IMPORTANCE OF THE ETHNOCULTURAL COMPONENT IN THE PROCESS OF TEACHING CHINESE STUDENTS THE RUSSIAN LANGUAGE Wang Chunhong}

Summary: This article discusses the importance of the ethnocultural component in the process of teaching Chinese students the Russian language. It is substantiated that the specifics of teaching Russian as a foreign language is associated not only with the psychological personality characteristics of Chinese students, but also with the ethnocultural component, the characteristics of the nation, and the originality of the native language, culture, etc. Problems and main difficulties in mastering the Russian language in the Chinese audience are identified. outside the language environment. Means and methods are described for Chinese students to master the Russian language, taking into account the ethnocultural component.

The importance of the regional geographical aspect of the study of the Russian language by the Chinese audience is noted. The author comes to the conclusion that only the practical application of cultural knowledge, "immersion" in another culture, direct mastery of the language of culture contributes to the understanding of other cultures, and a comparative analysis of ethnocultural components focused on intercultural communication helps to better understand their own cultural values. In this connection, the ethnocultural component in the process of teaching Chinese students the Russian language is important and contributes to a more effective mastery of the Russian language by the Chinese audience.

Keywords: Russian as a foreign language, culture, regional studies, intercultural communication, Chinese, Chinese audience, ethnocultural component, methods of teaching Russian as a foreign language, Chinese educational system, language environment, learning content, educational traditions.
$\mathrm{B}$ качестве фактора, увеличивающего успешность процесса обучения русскому языку как иностранному, выступает учет национально-психологической и национально-культурной специфики. Это обусловлено тем, что особенность изучения любого иностранного языка зависит как от психологической индивидуальной специфики студента, так и от этнопсихологической специфики нации и самобытности родного языка, культуры и т. п. «Знания о ментальных особенностях, определяющих эмоциональные реакции, специфику мышления и национального менталитета помогают более успешно и эффективно выстроить план обучения» [1, с.229].
Ван Чуньхун

Дочент, Институт иностранных языков Цзилиньского педагогического университета, город Сыпин, провинция Цзилинь, Китай wbcd123@sina.com

Аннотация: В настоящей статье рассматривается значение этнокультурного компонента в процессе обучения китайских студентов русскому языку. 0боснованно, что специфика обучения русскому языку как иностранному связана не только с психологическими личностными особенностями китайских студентов, но и сэтнокультурным компонентом, особенностями нации и своеобразием родного языка, культуры и т. п. Выявлены проблемы и основные трудности в овладении русским языком в китайской аудитории вне языковой среды. Характеризуются средства и методы для овладения китайскими студентами русским языком с учетом этнокультурного компонента.

Отмечается важность страноведческого аспекта изучения русского языка китайской аудиторией. Автор приходит к выводу, что только практическое применение культурологических знаний, «погружение» в другую культуру, непосредственное овладение языком культуры способствует пониманию других культур, а сравнительный анализ этнокультурных компонентов, ориентированной на межкультурное общение, помогает лучше осознать и собственные культурные ценности. В связи с чем, этнокультурный компонент в процессе обучения китайских студентов русскому языку играет важное значение и способствует более эффективному овладению русским языком китайской аудитории.

Ключевые слова: русский язык как иностранный, культура, страноведение, межкультурная коммуникация, китайский язык, китайская аудитория, этнокультурный компонент, методика преподавания русского языка как иностранного, образовательная система Китая, языковая среда, содержание обучения, образовательные традиции.

Разделяем позицию, что «процесс обучения на иностранном языке целесообразно осуществлять принимая во внимание специфику межкультурного взаимодействия и национально-культурных особенностей учащихся, формируя положительные психологические условия для обучения» [2, с.147].

По справедливому уточнению некоторых ученых, в процессе изучения китайской аудиторией русского языка следует сосредоточиться не только на методике, а этнометодики, способствующей правильному выбору нужного способа, инструмент, технологии обучения, эффективному планированию педагогической коммуника- 
ции» [3]

Отметим, что особенностью китайских студентов является то, что по прибытию в Россию, находясь в языковой среде, они не тянуться к коммуникации с носителями языка несмотря на то, что много занимаются. Китайские студенты, в основном, предпочитают контактировать со своими соотечественниками на китайском языке и общаются на русском языке в необходимых случаях.

Тем самым китайские студенты читают литературу, слушают аудио материалы, просматривают видео материалы на русском языке, при этом не разговаривают в обычной жизни на русском языке. Указанное обусловлено следующими обстоятельствами:

- китайцы достаточно скрытные с психологической точки зрения, флегматичные. Они смущаются первыми начинать коммуникацию с кем либо;

- воздействие классической методики преподавания и образовательной системы Китая. В частности, в КНР основная цель ученика - это запоминание большого массива информации и его последующее воссоздание (пересказ). При этом не требуется ни анализа учебного материала, ни высказывания собственного мнения относительно данного материала. Тем самым, китайская система образования не способствует развитию умений прогнозирования содержания текста по его заголовку, по ключевым словам, по началу предложения или слова.

В связи с чем, большая часть китайцев использует некоммуникативный метод изучения иностранных языков. То есть, они без проблем выполняют подстановочные упражнения, но речевые навыки представляют для них сложность. Поэтому китайские студенты достаточно не просто психологически идут на коммуникацию, пока не будут в усвоенной лексике и грамматике несмотря на то, что фактически они уже хорошо знают правила русского языка.

По нашему мнению, указанное обусловлено особенностями китайского менталитета. Например, отмечается, что «у китайцев есть понятие чести, в буквальном смысле означающее «лицо». То есть это страх ошибиться и потерять свое «лицо» в социуме» [4, с.14-21]. Так называемая потеря лица для китайцев не приемлема. Указанное обуславливает сдержанное поведение китайцев без активного выражения собственного мнения публично.

Также следует отметить, что одной из причин значительных различий между китайской культурой, менталитетом и образом мыслей и иных культур является то, что китайцы используют в своей письменности иероглифы, в то время как большая часть остальных наций пользуется буквенной или слоговой азбукой.
В результате применения иероглифов образ мыслей китайцев конкретно-символический, у них наиболее развит зрительный и зрительно-двигательный тип памяти. Данная особенность коренным образом отличает китайских студентов как этническую группу от студентов, у которых родной язык более близок к русскому [5, с. 85].

В связи с чем, принимая во внимание специфику образа мыслей китайцев, по нашему мнению, для китайских студентов в период обучения русскому языку целесообразно применять графическую и предметную наглядность.

Поскольку для рассматриваемой этногруппы наиболее удобна вопросно-ответная деятельность, описание, пересказ, сочинение, чтение текстов, то в процессе обучения китайских студентов русскому языку необходимо принимать во внимание особенности их национальных дидактических стереотипов. А именно: зрительная наглядность, применение семантизации, толкования и перевода, четкое инструктирование, применение вопросно-ответной формы, и т.п. При этом, полагаем обоснованным внедрение в процесс обучения китайских студентов русскому языку более эффективных и инновационных средств и методов обучения.

Разделяем позицию Т.М. Балыхиной, что актуальность исследования специфики китайского языка в сравнении с русским обусловлена реальной потребностью в описании, уточнении и аргументировании сложностей, с которые возникают у китайских студентов в процессе изучения русского языка, познания русской культуры [6, c. 17].

Некоторые исследователи отмечают, что анализ этнокультурных компонентов китайского языка и культуры в сравнении с этнокультурными компонентами русского языка и культуры увеличивает заинтересованность китайской аудитории к познанию учебного материала. Это обусловлено тем, что при сравнении через призму китайского языка и культуры китайские студенты познают российскую культуру. Что, в свою очередь, позволяет китайской аудитории приобрести дополнительные факультативные знания, стимулирует их познавательную деятельность [7, с. 54].

В связи с чем, по нашему мнению, этнокультурный компонент представляет особую важность в процессе обучения китайских студентов русскому языку. Особенно большое значение имеет сопоставление таких различных языков, как русский и китайский.

Как известно, одной из основных функций языка является возможность выражать собственными речевыми средствами образы своей и другой культуры. Поэтому, при обучении китайских студентов русскому языку, осо- 
бую актуальность представляет учет этнокультурного компонента в сегодняшних учебных пособиях, развитие межкультурной лексической, фразеологической компетентности.

В связи с этим значимую роль в учебном процессе при подготовке китайских студентов занимает страноведческий аспект изучения русского языка. Это обусловлено многими причинами: научно-методическими, культурологическими, общественно-политическими, в том числе и экономическими (наличие тесных торговоэкономических отношений между РФ и КНР).

Для выявления значения этнокультурного компонента в процессе обучения китайских студентов русскому языку нами выделены некоторые сложности в изучении русского языка китайской аудитории вне языковой среды, которые представлены внизу.

Кроме того, значение этнокультурного компонента в процессе обучения китайских студентов русскому языку можно проследить с помощью страноведения. В курсе страноведения одной из главных тем является тема русской культуры, которая включает в себя язык, литературу, религию, традиции, быт и др. В число основных задач страноведения входит познание генезиса русской культуры, знакомство китайских студентов с главными ее явлениями и наиболее яркими представителями. Это обусловлено тем, что непосредственно с помощью исследования культурных традиций и достижений более глубоко познается душа народа, его менталитет и идеалы.

Также в качестве специфической черты курса страноведения выступает наличие взаимного диалога культур и социумов при изучении данного курса. Ему сопутствует сопоставление китайскими студентами исторических и нынешних явлений, происходящих в России РФ с социальной практикой и общественным пониманием реалий жизни в Китае. В связи с чем, изучение страноведения России обусловлено насущими проблемами жизнедеятельности и культуры родной страны китайских студентов, а также с эволюцией мировой цивилизации и существенной оживлением экономических, политических и культурных контактов между странами и их населением.

Между тем, обратим внимание, что этнокультурную, коммуникативную и социальную компетенции, нельзя сформировать одной учебной литературой. В данном случае немаловажную роль играют практические умения и навыки, которые следует развивать наряду с освоением учебного материала. Это обусловлено тем, что лишь практическое использование культурных познаний позволяет личности понимать иные культуры. Более того, сравнительный анализ этнокультурных компонентов, направленный на межкультурное общение, способствует более эффективному пониманию своих культурных ценностей. Указанное достигается с помощью языка культуры.

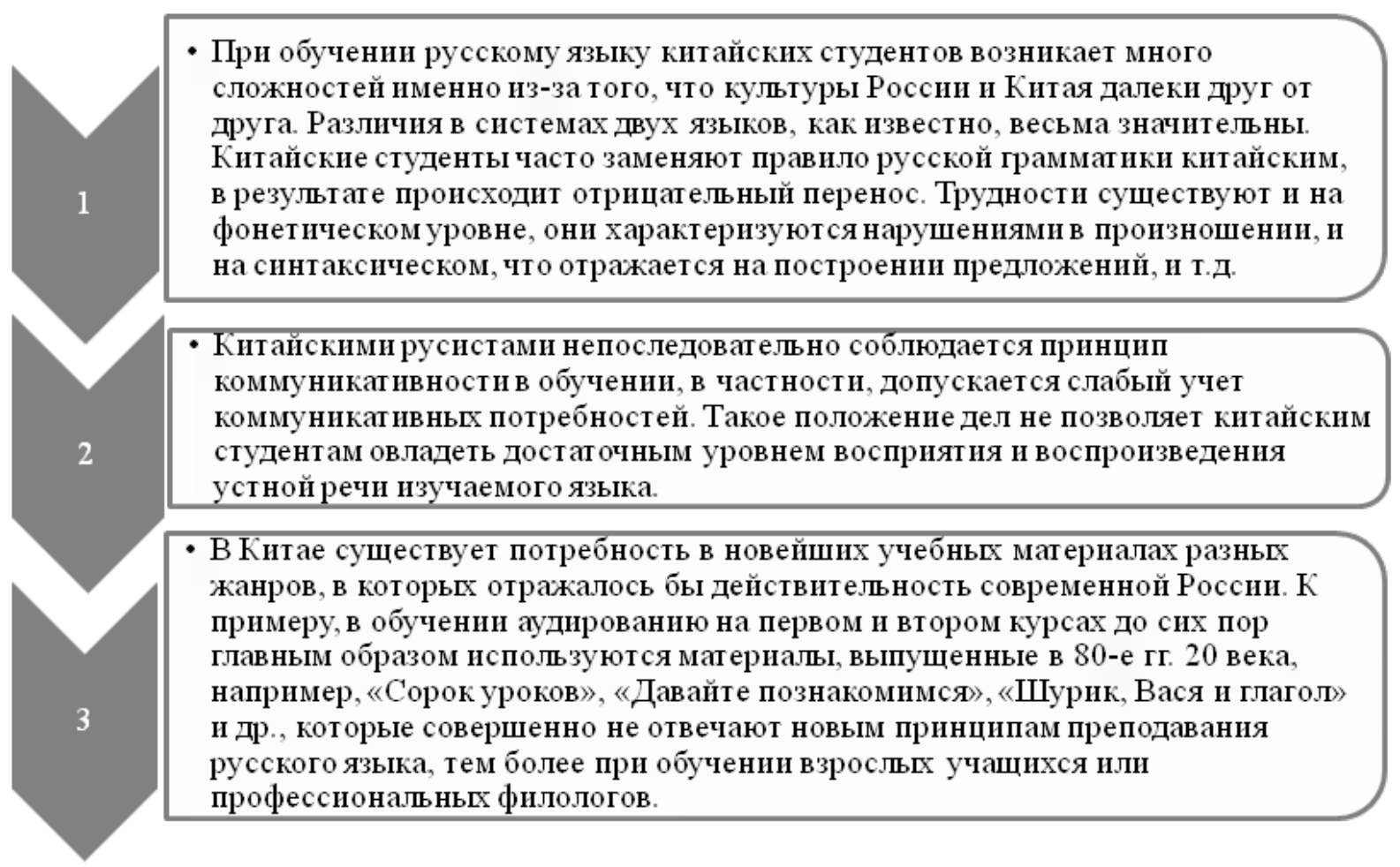

Сложности в изучении русского языка китайской аудитории вне языковой среды 
Под языком культуры в широком смысле подразумеваются инструменты, знаки, формы, символы, тексты, помогающие индивидам осуществлять взаимную коммуникацию, осваиваться в сфере культуры. Язык культуры представляет собой разностороннюю форму осознания реальности, где «организуются все возникающие или уже имеющиеся представления, восприятия, понятия, образы и иные смысловые конструкции» [8, с. 35].

Обратим внимание, что имеющаяся до сих пор проблема языка культуры - это проблема понимания, проблема успешности и культурного диалога между культурами разных эпох, и диалога разных культур, существующих одновременно, между собой.

Проведенный анализ показал, что китайским студентам, изучающим русский язык, помимо хороших знаний грамматики, разнообразного лексического запаса и хорошего произношения, следует развивать в себе межкультурную компетенцию. Она включает в себя возможность налаживания коммуникаций с представителями русской культуры, знания специфики образа жизни русского человека. Данная компетенция предусматривает овладение такими навыками как:

- комментировать и сопоставлять разные культурные системы друг с другом;

- бороться с сопротивлением, «конфликтами», характерными для межкультурной коммуникации.

Составные компоненты межкультурной компетенции представлены внизу.

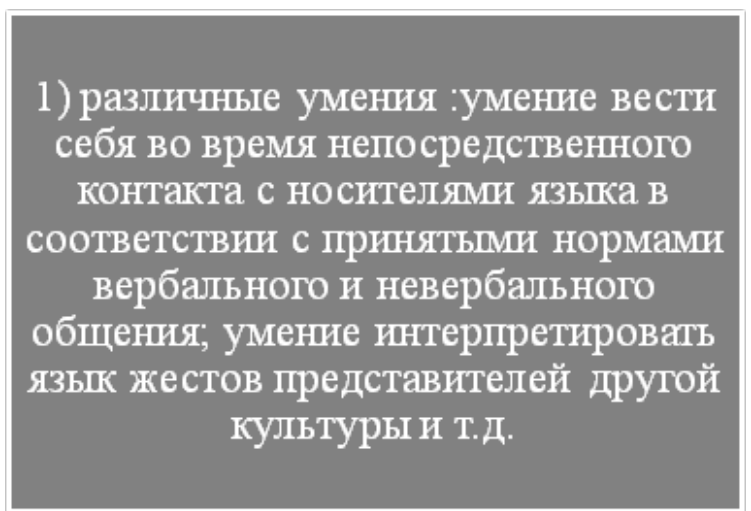

Отметим, что большое значение в достижении вышеперечисленных умений и знаний имеет внеурочная работа.

Итак, можно сделать вывод, что комплексный, интегративный характер страноведения России является его отличительной чертой. Это находит свое выражение в трех аспектах [9, с. 64]:

1. Изучение различных сторон жизни народа в учебном процессе (например, формирования российской государственности и современных политических процессов, федеративного политического устройства и национальной политики, экономики, культуры, науки и образования и др.).

2. В связи с ограниченностью учебного времени преподаватель не может раскрыть отдельные проблемы более глубоко. Однако в различных пособиях представлено множество материалов, чтобы студенты могли познакомиться с ними. В этом смысле особую важность приобретают различные формы самостоятельной работы учащихся.

3. Очень продуктивными в работе со студентами по выработке навыков совершенствования процесса мышления на изучаемом русском языке являются внеклассные формы работы.

Проведенный нами анализ, позволяет прийти к выводу, что этнокультурный компонент в процессе обучения китайских студентов русскому языку играет важное значение и способствует более эффективному овладению русским языком китайской аудитории. С помощью куль-

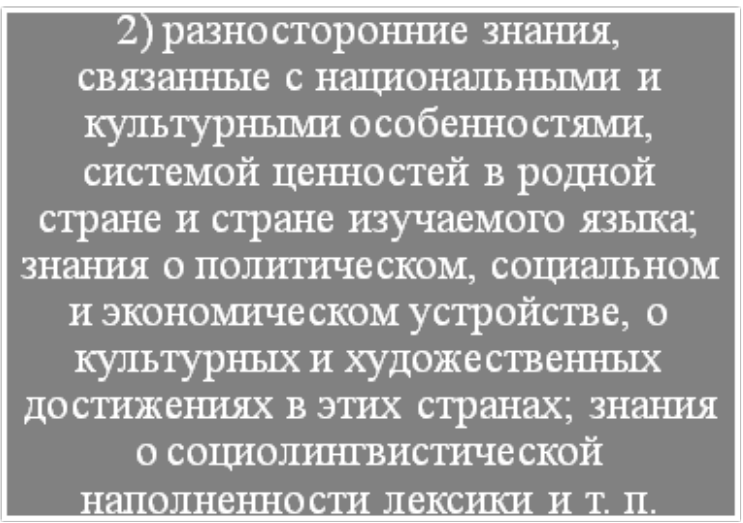

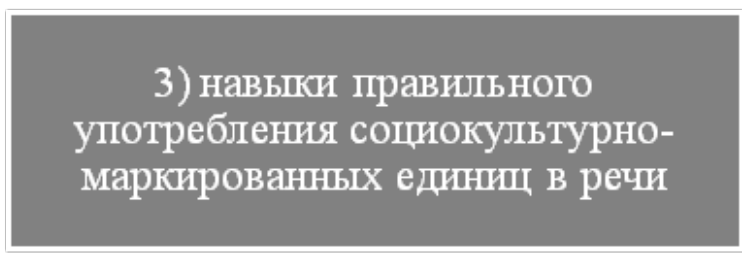

Составные компоненты межкультурной компетенции 
турологических познаний, выраженных в языке культуры народа-носителя языка, дружественного отношения китайских специалистов к России возможно развитие более продуктивных российско-китайских отношений в различных сферах.

В целях поддержания мотивации китайских учащихся в овладении русским языком как иностранным и оп- тимизации обучения важно учитывать этнокультурный компонент в процессе обучения китайских студентов русскому языку, а также опираться на развитые и устойчивые стороны этнопсихики: высокий уровень мнемических способностей, развитую интуицию, зрительный канал восприятия и зрительно-двигательный тип памяти, активное использование аналогии, контекстуальной догадки и др.

\section{ЛИТЕРАТУРА}

1. Шантурова Г.А. К вопросу о роли этнопсихологических факторов в обучении РКИ китайских студентов-русистов. Методика преподавания РКИ: традиции и современность. Сборник материалов научно-практической конференции (к сорокалетию кафедры преподавания РКИ). М., 2015. -268 с.

2. Сурыгин А.И. Основы теории обучения на неродном для учащихся языке. СПб.: Издательство «Златоуст», 2000. - 233 с.

3. Балыхина Т.М., Чжао Юйцзян. От методики к этнометодике. Обучение китайцев русскому языку: проблемы и пути их преодоления: Монография — 2-ое издание. М.: РУДН, 2010, — 344с.

4. Фахрутдинова М.Т. Этнопсихологические особенности изучения русского языка как иностранного. В мире науки и искусства: вопросы филологии, искусствоведения и культурологии: Сб. ст. по матер. LVI междунар. науч.-практ. конф. № 1(56). Новосибирск: СибАК, 2016.

5. Бобрышева И. Е. Культурно-типологические стили учебно-познавательной деятельности иностранных учащихся в методике обучения русскому языку как иностранному. М.: Флинта. Наука, 2004. - 256 с.

6. Балыхина Т.М., Чжао Юйцзян. Какие они, китайцы? Этнометодические аспекты обучения китайцев русскому языку. Высшее образование сегодня. 2009. № 5. C. 16-22

7. Рубина С.Н. Лингвострановедческий подход к презентации русской фразеологии в китайской аудитории. Диссертация кандидата педагогических наук, Волгоград: 2000. -173 с.

8. Парахонский Б.А. Язык культуры и генезис знания [Текст] /Б.А. Парахонский. Киев: Наукова думка, 1988. -212 с.

9. Тер-Минасова С.Г. Язык и межкультурная коммуникация. - М., Изд-во «Слово/Slovo», 2000. - 260 c.

(c) Ван Чуньхун (wbcd123@sina.com).

Журнал «Современная наука: актуальные проблемы теории и практики»

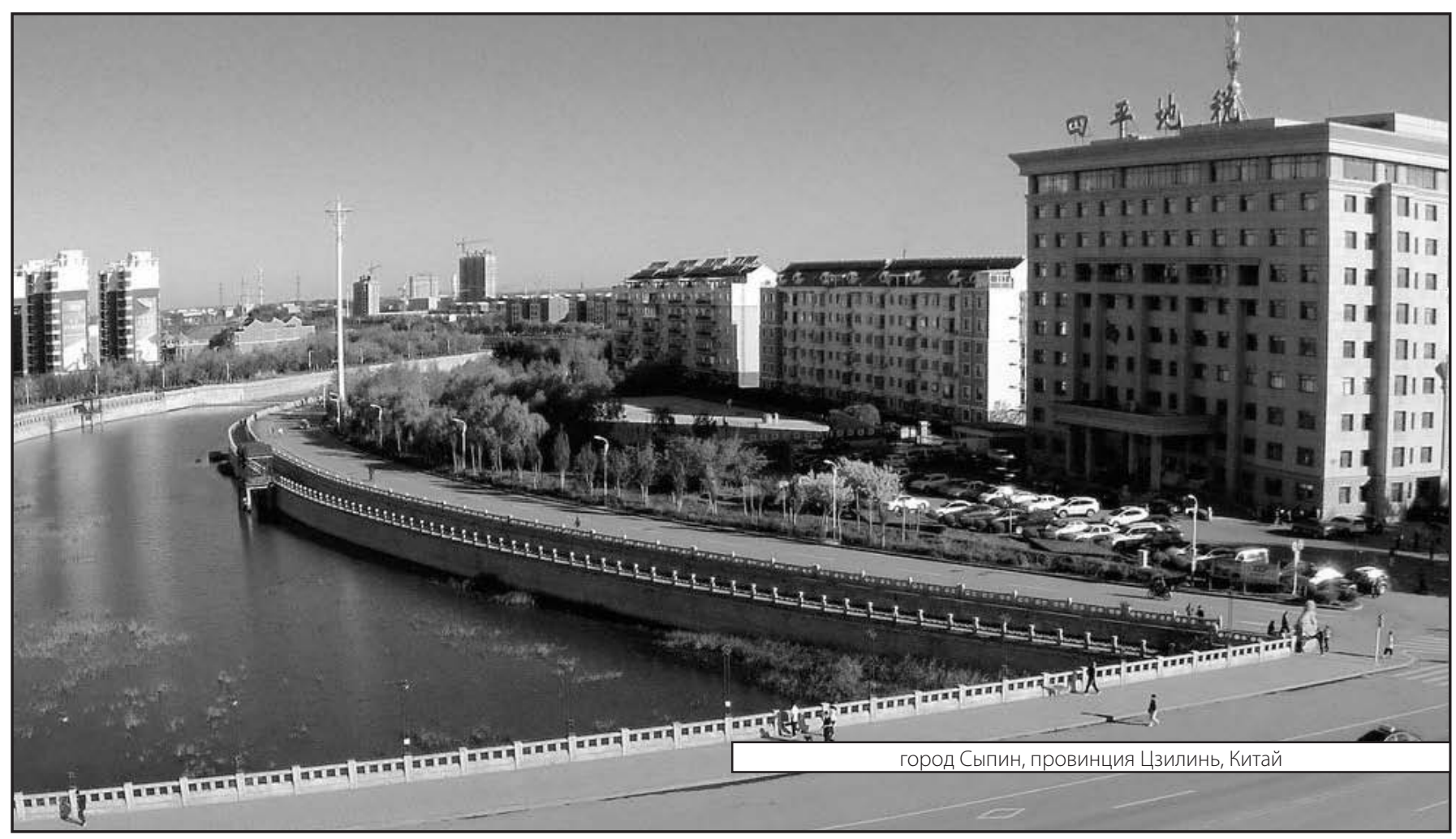

